\title{
Effect of hormonal and copper IUDs on genital microbial colonisation and clinical outcomes in North-Western Nigeria
}

\author{
Abdulhadi D. Saidu' ${ }^{1 *}$, Karima A. Tunau ${ }^{1}$, Abubakar A. Panti ${ }^{1}$, Emmanuel I. Nwobodo', \\ Yahaya Mohammed ${ }^{2}$, Jamila Amin ${ }^{3}$, Jamila A. Garba ${ }^{1}$
}

\begin{abstract}
${ }^{1}$ Department of Obstetrics and Gynaecology, ${ }^{2}$ Department of Medical Microbiology and Parasitology, ${ }^{3}$ Department of Community Health, Usmanu Danfodiyo University Teaching Hospital, Sokoto Nigeria
\end{abstract}

Received: 15 March 2017

Accepted: 21 April 2017

\section{*Correspondence:}

Dr. Abdulhadi D. Saidu,

E-mail: sabdulhadidiyo@gmail.com

Copyright: (c) the author(s), publisher and licensee Medip Academy. This is an open-access article distributed under the terms of the Creative Commons Attribution Non-Commercial License, which permits unrestricted non-commercial use, distribution, and reproduction in any medium, provided the original work is properly cited.

\begin{abstract}
Background: Intrauterine devices are one of the popular long term reversible contraceptive methods. Earlier forms were associated with genital infections, however more recent types such copper IUDs and hormonal types have been shown to have better safety profile. However, there is no conclusive evidence to demonstrate that hormonal IUD is less associated with genital infection when compared with copper IUDs. The objectives include determination of prevalence of genital tract infections among IUD users, to determine the type of IUD that is less associated with genital infection, and also determine clinical features seen among IUD users.

Methods: We conducted a descriptive, cross sectional study of clients who were at 6 months following IUD insertion. Endocervical and high vaginal samples were taken to isolate microbes.

Results: The prevalence of genital tract infection was $20 \%$ in Copper IUD users and $8.6 \%$ among LNG-IUS users. Genital infection was significantly higher among copper IUD users compared to hormonal IUD users $(\mathrm{p}=0.038, \mathrm{OR}=$ 2.88). Abnormal vaginal discharge was the commonest symptoms among IUD users and formal education was associated with less risk of genital infections $(\mathrm{p}=0.048)$.

Conclusions: Hormonal IUDs are less associated with genital tract infection compared to copper IUDs and women with formal education are less likely to have genital infection among IUD users.
\end{abstract}

Keywords: Copper IUD, Genital infection, LNG-IUS

\section{INTRODUCTION}

The suspicion that intrauterine devices (IUDs) could cause genital infections has a long history from 1940s. ${ }^{1}$ The introduction of newer IUDs including the hormonal type with the aim of improving its safety profile and efficacy has increased its popularity. ${ }^{2}$ So many studies have been conducted to identify IUD related infections. It is likely that the hormone in LNG-IUS could limit the ascent of microbes in the genital tract. The most acceptable conclusion is that IUD related infection is generally low but appears to be highest in the first month post insertion, suggesting that insertion procedure may be responsible. $^{3}$ This study assessed genital infection in copper containing IUD and LNG-IUS users in the NorthWestern part of Nigeria. The study set out to determine the prevalence of genital tract infections among IUD users; to determine common symptoms of genital infection among IUD users and to identify the type of IUD associated with genital infection.

\section{METHODS}

\section{Study area}

The study was conducted at the Family Planning clinics of the Usmanu Danfodiyo University Teaching Hospital (UDUTH), Sokoto. 
Design of the study was a cross-sectional study.

\section{Study population}

The study involved 70 clients who used IUD for six months, 35 used $\mathrm{Cu}-\mathrm{T} 380 \mathrm{~A}$ and 35 used LNG-IUS.

\section{Sampling method}

Eligible clients were recruited by convenience sampling method. A semi-structured questionnaire was used to obtain relevant information and all clients were recruited from September 2015 to June 2016.

\section{Sample collection}

An endocervical specimen was collected for culture using a sterile cotton swab during vaginal examination to detect Neisseria gonorrhea after inoculation into Thayer Martin and 5\% blood agar. The endocervical swab was also smeared onto a glass slide for Giemsa staining to detect Chlamydia trachomatis inclusion bodies. High vaginal swabs were taken to isolate for Trichomonas vaginalis, Candida species, Gardnerella vaginalis and anaerobes. One of the high vaginal swabs was used to make wet mount and Gram Staining, while the second swab was used for culture.

The swab sticks had Amies medium which served as transport medium used for the transport of samples to the laboratory.

The high vaginal swab was utilized to make the preparation for detection of Trichomonas vaginalis trophozoites, motile bacteria, Candida species, epithelial cells and pus cells.

Gram staining was used to identify gram negative diplococci denote Neisseria gonorrhea. Large Gram positive yeast cells and pseudohyphae seen could be Candida species. In bacterial vaginosis, epithelial cells with adhering gram negative organisms.

Giemsa staining was used to identify Chlamydial infection when blue-mauve coloured inclusion bodies were seen in epithelial cells.

Oxidase and Sugar fermentation test was performed on suspected Neisseria gonorrhea colonies. Neisseria gonorrhea colonies are Oxidase positive and ferment glucose but not lactose, maltose or sucrose. Catalase and coagulase test was employed to differentiate between the Gram positive cocci. Staphylococcus aureus is catalase and coagulase positive while Streptococcus agalactiae is catalase negative. Candida species was further confirmed to their specie level by the use of Germ tube test and sugar assimilation test. Candida albicans is germ tube positive, while other species are negative.

\section{Data analysis}

The results obtained were analysed using Statistical Package for Social Sciences (SPSS) version 21. A pvalue of $<0.05$ was considered significant. Chi square was used to determine association and significant parameters were subjected to logistic regression.

\section{RESULTS}

A total of 70 women were enrolled for this study. The mean age of the respondents with copper IUD was $28.94 \pm 7.1$ years and that of the hormonal IUD group was $27.90 \pm 6.7$ years. Most of the respondents were between 25-34 years of age. The majority of the respondents were unemployed, $45(64.3 \%)$ and mostly in monogamous setting. Majority of the respondents were formally educated and only $9(25.5 \%)$ had no formal education. Most $(78.6 \%)$ of the women had 1-5 previous deliveries (Table 1).

Table 1: Socio-demographic characteristics of respondents.

\begin{tabular}{|c|c|c|}
\hline \multirow[t]{2}{*}{ Characteristic } & \multicolumn{2}{|c|}{ Frequency (\%) } \\
\hline & Copper IUD & LNG-IUS \\
\hline \multicolumn{3}{|l|}{ Age (years) } \\
\hline$<20$ & $9(25.7)$ & $12(34.3)$ \\
\hline $20-30$ & $20(57.1)$ & $17(48.6)$ \\
\hline$>30$ & $6(17.1)$ & $6(17.1)$ \\
\hline \multicolumn{3}{|l|}{ Occupation } \\
\hline Unemployed & $20(57.1)$ & $25(71.4)$ \\
\hline Employed & $15(42.9)$ & $10(11.4)$ \\
\hline \multicolumn{3}{|l|}{ Type of family } \\
\hline Monogamous setting & $19(54.3)$ & $18(51.4)$ \\
\hline Polygamous setting & $16(45.7)$ & $17(48.6)$ \\
\hline \multicolumn{3}{|l|}{ Educational status } \\
\hline No formal education & $5(14.3)$ & $4(11.2)$ \\
\hline Formal Education & $30(85.7)$ & $31(88.8)$ \\
\hline \multicolumn{3}{|l|}{ Parity } \\
\hline $1-5$ & $27(77.1)$ & $28(80.0)$ \\
\hline $6-10$ & $8(22.9)$ & $7(20.0)$ \\
\hline
\end{tabular}

Table 2: Common symptoms of genital infection among IUCD users.

\begin{tabular}{|lll|}
\hline Symptom & Number & Percentage \\
\hline Lower abdominal pain & 4 & 5.7 \\
\hline Dyspareunia & 0 & \\
\hline Abnormal vaginal discharge & 8 & 11.4 \\
\hline Abnormal vaginal bleeding & 2 & 2.9 \\
\hline Urethral discharge & 0 & \\
\hline Cervical excitation tenderness & 0 & \\
\hline Adnexal tenderness & 0 & \\
\hline
\end{tabular}

Abnormal vaginal discharge was the commonest symptom at 6 month, it was identified in $8(11.4 \%)$ of the respondents (Table 2). 
At 6 months, 7 (20\%) women who used copper IUCD and $3(8.6 \%)$ women who used LNG-IUS had genital infection. The observed difference was statistically significant $\left(\chi^{2}=6.066, p=0.022\right)$ (Table 3$)$. Women with copper IUD are more than two times more likely to have genital infections $(\mathrm{OR}=2.88)$ (Table 4$)$.

Table 3: Association of IUD types and infection.

\begin{tabular}{|lll|l|}
\hline \multirow{2}{*}{ IUD } & \multicolumn{2}{l|}{ Infection $(\%)$} & Test of \\
& No & Yes & significance \\
\hline Copper T & $28(80)$ & $7(20)$ & $\chi^{2}=6.066$ \\
\hline LNG-IUS & $32(91.4)$ & $3(8.6)$ & $\mathrm{p}=0.022^{*}$ \\
\hline
\end{tabular}

*significant association

Table 4: Logistic regression model.

\begin{tabular}{|lll|ll|}
\hline B & WALD & P value & OR & $95 \%$ CI \\
\hline 2.064 & 5.274 & 0.038 & 2.88 & $1.35-45.83$ \\
\hline
\end{tabular}

Socio-demographic characteristics were analysed for association with genital infection among IUD users. Only educational status had statistically significant association with genital infection $\left(\chi^{2}=0.315, \mathrm{p}=0.048\right)$. This implies that women who were not formally educated and had IUD were more likely to have genital infection after six month of insertion (Table 5).

Table 5: Risk factors associated with genital infections in IUD users.

\begin{tabular}{|llll|}
\hline \multicolumn{5}{|c|}{ Factors } & No & Yes \\
\hline Age & & & \\
\hline$<20$ & $16(76.2)$ & $5(23.8)$ & $\chi^{2}=4.993$ \\
$20-30$ & $28(75.7)$ & $9(24.3)$ & $\mathrm{p}=0.141$ \\
$>30$ & $9(75.0)$ & $3(25.0)$ & \\
\hline Occupation & & & \\
\hline Employed & $33(73.3)$ & $12(26.7)$ & $\chi^{2}=0.215$ \\
Unemployed & $17(68.0)$ & $8(32.0)$ & $\mathrm{p}=0.728$ \\
\hline Edu. Status & & & \\
\hline Informal & $10(52.6)$ & $9(47.4)$ & $\chi^{2}=5.315$ \\
Formal & $40(67.7)$ & $11(21.3)$ & $\mathrm{p}=0.048^{*}$ \\
\hline Family setting & & & \\
\hline $\begin{array}{l}\text { Monogamy } \\
\text { Polygamy }\end{array}$ & $28(75.3)$ & $9(24.3)$ & $\chi^{2}=1.39$ \\
\hline Parity & & & $\mathrm{p}=0.29$ \\
\hline $\begin{array}{l}\text { Para 1-5 } \\
\text { Para 6-10 }\end{array}$ & $10(72.3)$ & $15(27.3)$ & $\chi^{2}=1.893$ \\
\hline
\end{tabular}

* Significant association

\section{DISCUSSION}

The prevalence of genital infection among IUD users was $20 \%$ and $8.6 \%$ among copper IUD and LNG-IUS users respectively. However higher rates were observed in Benin, Nigeria where $53.07 \%$ of IUD users who presented with complain had laboratory confirmation of genital infection. ${ }^{4}$ Alawad et al, in Sudan had prevalence of genital infection to be $65 \%$ among IUD users, but only clients with complain or ready for removal were recruited for the study. ${ }^{5}$ In West Bank, $91 \%$ of women using IUD complain of symptoms which may be related to genital infections. ${ }^{6}$ A lot of non-specific symptoms including fever and abdominal pain were considered in the study which was responsible for the high prevalence. These studies were cross sectional and there were gross variations in duration of IUD use. While some clients had, it inserted for few days, some had used it for more than 7 years. This may be responsible for the difference in prevalence rate. Additionally, the observed differences in these studies may also be due to differences in the types of IUCDs used by the clients. These could also be due to high prevalence of genital infection in the general population although, the infection status of the clients was not known prior to insertion of IUD. In Mumbai Shingade et al, reviewed women with clinical diagnosis of genital infection and $27.81 \%$ had IUD. ${ }^{7}$ This contrast our study where IUD use is the basis for inclusion not genital infection. In study from Bangladesh, $64.7 \%$ of the IUD users had genital tract infection the study was carried out among women with gynaecological complaints. ${ }^{8}$ Ruyer et al found $55.9 \%$ of women with IUD and vaginal discharge had laboratory evidence of genital infection. Since vaginal symptom is a symptom of genital infection, it's not surprising that microbes were isolated from many of the women. ${ }^{9}$ Sangita et al found $22.3 \%$ of IUD users had pelvic inflammatory disease. ${ }^{10}$ Patients were recruited at the gynaecological outpatient clinic which could have caused selection bias and more so, only upper genital tract infection was also studied.

The common clinical features recognized among IUCD users in this study were vaginal discharge and lower abdominal pain. At 6 months $12.2 \%$ and $6.1 \%$ of the women had abnormal vaginal discharge and lower abdominal pain respectively. Similarly in studies conducted in Sudan and Turkey, abnormal vaginal discharge was the commonest symptom among IUCD users., ${ }^{5,11}$ In Palaestine, lower abdominal pain was the commonest symptom. ${ }^{6}$ Menorrhagia was the main complaint of IUCD users in an Iranian study while backache and abnormal vaginal discharge were the major symptoms of the clients with IUCD in an Indian study. ${ }^{12,13}$ In the non-IUCD group, abnormal vaginal bleeding was the commonest symptom in this study and this may have been contributed by relative high number women who used implants in this group.

It was observed in this study that copper IUCD was significantly associated with genital infection when compared with hormonal IUCD at six months $\left(\chi^{2}=6.066\right.$, $\mathrm{p}=0.022$ ). Interestingly, when this association was subjected to logistic regression analysis it was found to be significant, women with copper IUCD were 2.8 times more likely to have genital infection at third contact $(\mathrm{OR}=2.88, \mathrm{p}$ value $=0.038, \mathrm{CI}=1.35-45.83)$. Serap et al found that copper IUD to be associated with an alteration on vaginal flora and higher frequency of nonspecific 
inflammatory changes affecting cervical cytology but this was not seen with LNG-IUS. ${ }^{14}$ The women used the IUDs for 12 months before tests were done and hence the patterns of infection in the first few weeks to months were not determined. Toivonen also found levonorgestrel IUD to have protective effect against pelvic inflammatory diseases compared to NOVA-T after 36 months of use $(p<0.013) .{ }^{15}$ Infection of the lower genital tract was not determined in the study. The incidence of pelvic inflammatory disease was low among LNG-IUS users regardless of the age. In NOVA-T, pelvic inflammatory disease was increased among the youngest women which makes the difference significant $(\mathrm{p}<0.01) .{ }^{16}$ In contrast, Sivin et al observed no difference in the cumulative rate of infection between levonorgestrel IUD and copper IUD users. Infection rates appear to be lowest in the sixth and seventh years of the study. ${ }^{17}$

Age, occupation, marital status, husband's number of partners, educational status, religion and parity were analysed for association with genital infection among users of IUCD. Only educational status had statistically significant association with genital infection $\left(\chi^{2}=5.315\right.$, $\mathrm{p}=0.048)$. Women who used IUCD and had formal education were less likely to have genital infection compared to those without formal education. Formally educated women are more likely to observe good personal hygiene because they have more access to health information. Studies from Sweden ${ }^{16}$ and Basra, Iraq showed that age was significantly associated with genital infection among IUCD users. Infection was higher among younger women. ${ }^{18}$

The prevalence of genital infection among IUD users was relatively high. Abnormal vaginal discharge was the most common symptom among IUD users. Genital infection was higher among copper containing IUD users compared to LNG-IUS. Formal education was associated with lower rate of genital infection among IUD users.

\section{ACKNOWLEDGMENTS}

Authors would like to acknowledge Dr. Yusuf Shuaibu, Dr. Umar I. Augie, Dr. Fatima B/ Yauri, Dr. Are Temitope, Dr. Innocent Ekele and Dr. Ummulkulthum Alhassan for their technical supports. They also appreciate the contribution of the nurses in the Family Planning Clinics in clients' counseling.

Funding: No funding sources

Conflict of interest: None declared

Ethical approval: The study was approved by the Institutional Ethics Committee of Usmanu Danfodiyo University Teaching Hospital

\section{REFERENCES}

1. Tietze C, Lewit S. Intrauterine contraceptives devices. Amsterdam: Excerpta Medica International Congress Series; 1962:54.
2. Hubacher D. Intrauterine device and infection: Review of the literature. Indian $\mathrm{J}$ Med Res. 2014;140:53-7.

3. Farley TM, Rosenborg MJ, Rowe PJ, Chen JH, Meirik O. Intrauterine device and pelvic inflammatory disease. Lancet. 1992;339:785-8.

4. Egbe CA, Onwufor UC, Omoregie R, Enabulele OI. Female reproductive tract infections among vaginal contraceptive users in Benin City, Nigeria. Genomic Medicine Biomarkers, and Health Sciences. 2011:3(2):49-52.

5. Alawad A, Bashir ME. Association of infection among intrauterine contraceptive device users in family planning clinics in Sudan. Int $\mathrm{J}$ Health. 2014;2(2):50-60.

6. Musmar SG, Musmar M, Isma MA. Effect of IUD (intrauterine device) on reproductive tract infection (RTI) in the northern Westbank. Middle East Journal of Family Medicine (Online) 2004;5(5). Available from:

http://mejfm.com./journal/MEJFM\%20May\%20201 4/IUD1.htm. Accessed on 03/12/2015

7. Poonam PS, Naveen CK. Intruterine devices and reproductive tract infections: a cross-sectional study in urban slum. National $\mathbf{J}$ Comm Med. 2015;6(4):575-8.

8. Ruyer D, Mehmet D, Hamdi S, Yaprak E, Eren A, Halil B. Infection frequency among intrauterine copper T-380A contraceptive users, Acter Medica Mediterranea. 2013;29:489-92.

9. Patel SV, Baxi RK, Kotecha PV. A case control study of pelvic inflammatory disease and its association with IUD. J Obstet Gynecol India. 2008,54(4):333-7.

10. Kabir AK, Jaynul I, Shirin A. A study on prevalence of reproductive tract infections amongst women attending in an urban clinic. Chattagram Maa-OShishu Hospital Medical College Journal. 2014;13(1):32-5.

11. Ocak S, Cetin M, Hakverdi S, Dolapcioglu K, Gungoren A, Hakverdi A. Effects of intrauterine device and oral contraceptive on vaginal flora and epithelium. Saudi Med J. 2007;28(5):727-31.

12. Shobeiri F, Nazari M. Vaginitis in intrauterine contraceptive device users. Health. 2014;6(11). Available from: http://creative commons.org/licences/by/4.0[accessed February, 2016].

13. Agarwal K, Sharma U, Acharya V. Micrbiological and cytopathological study of intrauterine contraceptive device users. Indian J Med Sci. 2004;58(9):394-9.

14. Serap S, Aysel D, Aylin A, Hassan K. The impact copper-containing and levonorgestrel-releasing intrauterine contraceptives on cervicovaginal cytology and microbiological flora: A prospective study. European J Contracep Reprod Health Care. 2014;19(3):187-93.

15. Toivonen J, Luukkainen T, Allonen H. Protective effect of intrauterine release of levonorgestrel on 
pelvic infection: Three years' comparative experience of levonorgestrel- and copper-releasing intrauterine devices. Obstet Gynaecol. 1991;77(2):261-4.

16. Anderson K, Odlind V, Rybo G. Levonorgestrel releasing and copper releasing (Nova T) IUDs during 5years of use: a randomised comparative trial. Contraception. 1994;49:56-72.

17. Sivin I, Stern J, Coutinho E, Mattos CE, Mahgoub S, Diaz S. Prolonged intrauterine contraception: A seven year randomised study of the levonorgestrel 20mcg/day and copper T380A IUD. Contraception. 1991;44:473-840.
18. Sharief M. Genital infections among women using various contraceptive methods in Basra, Iraq. Eastern Mediterranean Health Journal. 1998;4(3):487-92.

Cite this article as: Saidu AD, Tunau KA, Panti AA, Nwobodo EI, Mohammed Y, Amin J, et al. Effect of hormonal and copper IUDs on genital microbial colonisation and clinical outcomes in North-Western Nigeria. Int J Reprod Contracept Obstet Gynecol 2017;6:2143-7. 